\title{
Integrating Natural Resources Education and Citizen Science Communication through the Use of Unmanned Aerial Systems (Drones)
}

\author{
David Kulhavy ${ }^{1}$, Daniel Unger ${ }^{1}$, I-Kuai Hung ${ }^{1}$, Chris Schalk ${ }^{1}$, Yanli Zhang ${ }^{1} \&$ Reid Viegut ${ }^{1}$ \\ ${ }^{1}$ Stephen F. Austin State University, USA \\ Correspondence: Daniel Unger, Stephen F. Austin State University, USA.
}

Received: September 17, 2021

Accepted: October 29, 2021

Online Published: November 2, 2021

doi:10.5430/ijhe.v11n2p143

URL: https://doi.org/10.5430/ijhe.v11n2p143

\begin{abstract}
Science communication is increasing through the use of Unmanned Aerial Systems (UAS) or drones. Within the Arthur Temple College of Forestry and Agriculture at Stephen F. Austin State University (SFASU), UASs such as the DJI Phantom 4 Pro and Mavic Mini2 drones were used by students and faculty to study mistletoe, crepemyrtle and fire ants and then drone images were uploaded to iNaturalist, the largest repository for flora and fauna specimens to share with the scientific community and general public. The benefits of using a UAS is that nadir (directly above) images of the specimens increase the locational accuracy of each specimen compared to distance images acquired from a smartphone. By incorporating drones into course works at SFASU, faculty are increasing the technological abilities of students to communicate natural resource information to a greater audience as a citizen scientist. With ever increasing capabilities and lower cost, UAS are becoming a viable alternative to smartphones for communication of science, especially for iNaturalist. The ability to communicate science information and display images adds a dimension for the citizen scientist to use a UAS in teaching and information exchange while creating a well-rounded, better informed, and more employable student upon graduation.
\end{abstract}

Keywords: drone, natural resources, conservation, citizen science, education

\section{Introduction}

Civic engagement or civic participation through citizen science is increasing to develop knowledge of species, gaining skills and competencies in community projects (Nugent \& Thrippleton-Hunter, 2017; Nugent, 2018). The involvement of citizens in science increases science communication related to people in their everyday lives. This exchange of dialogue and data enhances knowledge production incorporating both academic and those individuals interested in the advancement of science education. The 'active citizen' is now central to science communication and exchange of ideas and information (Wagenkenct et al. 2021) through open dialogs between researchers, citizens and stakeholders (Hoffman, Thompson Klein, \& Pohl, 2019).

iNaturalist (www.inaturalist.org) is one such platform that allows observers to share species' observations globally using a custom-made portal (van Horn et al., 2018) as an active citizen science project to communicate research, teaching or service endeavors by uploading observations to the site (Boone \& Basille, 2019). iNaturalist is expanding as a citizen scientist data acquisition system with the iNaturalist Challenge 2017 dataset containing 675,000 images of over 5,000 species of plants and animals (van Horn et al., 2018). In total, iNaturalist has over 73 million observations over 340,000 species with 4.2 million registered users using a web presence to collect observations from mobile smart devices, increasing the crowd-sourcing capability of citizen scientists in a "community-as-a-service" model for data collection and metadata validation (Cohen et al., 2015; He \& Wiggins, 2015). Exploring participation by younger citizens is growing for iNaturalist (Aristeidou et al., 2021) to connect people with nature, especially using mobile devices. This method tends to separate the individual from nature by providing a lens for observations (Altrudi, 2021). Challenges for citizen science include repositories for terabyte-scale multimedia, reliable mobile devices to retrieve spatial and temporal data, and accurate mapping capabilities (Kosmala, Wiggins, Swanson, \& Simmons, 2016).

On iNaturalist, digital vouchers for species identification and location are uploaded and verified online (Sullivan et al., 2009). Smartphones are often used as the primary tool for the user (citizen scientist) to collect georeferenced data (e.g., species related images). Within iNaturalist, the geospatial reference of the species is recorded and made available in the metadata set for each specimen image. The images are stored on the website where they can be 
verified by other community members (Teacher, Griffiths, Hodgson, \& Inger, 2013).

Mazumdar et al. (2018) documented emerging technologies for participation in citizen science for data collection, procession, visualization, and communication of ideas. One such emerging technology are Unmanned Aerial Systems (UASs) as the use of UASs is increasing in the conservation and management of natural resources (Evans et al., 2015) and can be used for science education and civic engagement such as iNaturalist. Pimm et al. (2015) promoted UASs with multispectral sensors, digital cameras and competitive costs using the iNaturalist model for crowdsourcing of data. For citizen scientists, many different UASs can be carried in a backpack, are relatively inexpensive, equipped with a capable camera, and can be flown after suitable instruction for safety and hands-on training (Sattar, Tamatea, \& Nawaz, 2017; Unger et al., 2019; Miller, Ziter, \& Koontz, 2021).

In teaching natural resources for science communication and applications to citizen science, the hands-on application of UASs employed by faculty at Stephen F. Austin State University (SFASU) motivates and engages students promoting active learning and knowledge creation while providing a learning environment for innovative solutions (Sattar, Tamatea, \& Nawaz, 2017). For science education, UASs requires connecting multiple concepts from safety, mission planning, carrying out the mission, downloading data, data processing, then preparing the final product including maps and citizen science material for iNaturalist (Sattar, Tamatea, \& Nawaz, 2017; Unger et al., 2019). Hands-on practice is essential to both motivate and engage students and is highly integrated into all course work at SFASU. As experience increases, confidence increases for the technical knowledge that leads to life and career skills. Continued use of UASs promotes problem solving and critical thinking skills to work with both geospatial science and technology information while using a UAS (Unger, Kulhavy, Busch-Petersen, \& Hung, 2016; Sattar, Tamatea, \& Nawaz, 2017). For these projects, students that completed the Mentored Undergraduate training (Unger, Kulhavy, Busch-Petersen, \& Hung, 2016) including synthesis of data and uploading to iNaturalist were selected as drone pilots and participants in the iNaturalist Drones and Biodiversity project.

In addition to their suitability in applications for various projects, UASs possess a number of components that make them ideal for integration into citizen science projects and educational endeavors, increasing their capabilities towards making observations on various subjects. In general, the components of an UAS include a GNSS (global navigation satellite system) receiver for positioning and airspeed of the aircraft; a camera for live view and taking images; an inertial measurement unit for aircraft maneuver; a controller for both the flight and the camera; and a flight data recorder for UAS position and altitude parameters for each image (Hugenholtz, Moorman, Ridddell, \& Whitehead, 2012; Whitehead \& Hugenholtz, 2014). To highlight how studies between natural resource management and citizen science can be integrated with the use of a UAS, we highlight the technology typically equipped in UASs while also highlighting several case studies undertaken by students within the Arthur Temple College of Forestry and Agriculture at SFASU that demonstrate the potential integration with citizen science below.

\section{Technology}

An UAS integrates a wide variety of technology into a user-friendly interface for operation. The advancement in material technology allows for lighter and stronger aircraft while the battery continues to increase maximum flight time. The improvement in sensor and GNSS technology equates to better control of the vehicle with greater precision, accuracy, and safety. The camera continues to pack more pixels into each frame, while the data transfer speed catches up with the demand for larger data files. The controller interface, usually on a mobile device such as a smartphone or tablet, is as important as the aircraft itself, particularly in citizen science involving general public to take part in a scientific data collection endeavor. When internet services continue to expand while the price becomes more affordable and the transfer speed increases at the same time, ultimately everyone becomes part of the Internet of Things (IoT).

In our case studies, students under supervision by faculty employed different UASs with different technical specifications (Table 1) after completing extensive UAS training. Within them, the DJI Mavic Mini 2 is the only one that can be operated when the environment temperature drops as low as $-10^{\circ} \mathrm{C}\left(14^{\circ} \mathrm{F}\right)$, while the DJI Spark drone can be controlled by hand gesture. Using each UAS to its highest potential is always our goal. Depending on the requirements of a project, the most appropriate UAS should be chosen. For example, for orthomosaic image and 3D model creation, DJI Phantom 4 Pro is the one to use due to its higher image resolution and capable of operating in a pre-planned flight mission. The Mavic Mini, flown using the app DJI Fly, with GPS + GLONASS for positioning, weighs $249 \mathrm{~g}$, just below the $250 \mathrm{~g}$ weight threshold that would require an FAA license in some areas is an excellent UAS candidate for educating students on the use of drones involved with citizen science communication and iNaturalist use. 
Table 1. Technical specification comparison for UASs

\begin{tabular}{|c|c|c|c|c|}
\hline & DJI Phantom 4 Pro & DJI Spark & DJI Mavic Mini & DJI Mavic Mini2 \\
\hline App & DJI GO 4 & DJI GO 4 & DJI Fly & DJI Fly \\
\hline Flight time (minutes) & 30 & 16 & 30 & 31 \\
\hline battery & $6,000 \mathrm{mAh}$ & $2,970 \mathrm{mAh}$ & $2,600 \mathrm{mAh}$ & $5,200 \mathrm{mAh}$ \\
\hline \multirow[t]{2}{*}{ Camera } & $1 " \mathrm{CMOS}$ & 1/2.3" CMOS & 1/2.3" CMOS & 1/2.3" CMOS \\
\hline & $20 \mathrm{MP}$ & $12 \mathrm{MP}$ & $12 \mathrm{MP}$ & $12 \mathrm{MP}$ \\
\hline Video & $4 \mathrm{k}$ & 1080 & $2.7 \mathrm{k}$ & $4 \mathrm{k}$ \\
\hline Stabilization & 3 -axis & 2-axis & 3 -axis & 3 -axis \\
\hline Speed (kph, max) & 72 & 50 & 46.8 & 57.6 \\
\hline $\begin{array}{l}\text { Range } \\
\text { controller, max) }\end{array}$ & $6,000 \mathrm{~m}$ & $2,000 \mathrm{~m}$ & $4,000 \mathrm{~m}$ & $10,000 \mathrm{~m}$ \\
\hline Obstacle sensing & $\begin{array}{l}\text { forward, backward, } \\
\text { TOF on both sides }\end{array}$ & forward & downward & downward \\
\hline $\begin{array}{l}\text { Max wind speed } \\
\text { resistance }\end{array}$ & $29-38 \mathrm{kph}$ & $20-28 \mathrm{kph}$ & $28.8 \mathrm{kph}$ & $29-38 \mathrm{kph}$ \\
\hline GNSS & GPS+GLONASS & GPS+GLONASS & GPS+GLONASS & GPS+GLONASS+GALILEO \\
\hline Operating temperature & $0^{\circ} \mathrm{C}-40^{\circ} \mathrm{C}$ & $0^{\circ} \mathrm{C}-40^{\circ} \mathrm{C}$ & $0^{\circ} \mathrm{C}-40^{\circ} \mathrm{C}$ & $-10^{\circ} \mathrm{C}-40^{\circ} \mathrm{C}$ \\
\hline $\begin{array}{l}\text { Max service ceiling } \\
\text { above sea level }\end{array}$ & $6,000 \mathrm{~m}$ & 4,000 & N/A & N/A \\
\hline Weight (g) & 1,388 & 300 & 249 & 249 \\
\hline
\end{tabular}

\section{Case Studies}

\subsection{Mistletoe}

Students used a DJI Phantom 4 Pro and a Phantom 4 version 2 UASs to document the presence and abundance of parasite load of mistletoe plants on hardwood trees (Kulhavy et al., 2019). The UAS allowed the students to capture high quality images of both the mistletoe plants and host trees that we posted to a project entitled Mistletoes of Nacogdoches (https://www.inaturalist.org/projects/mistletoes-of-nacogdoches) on iNaturalist.org (Figure 1). With each image acquired using a UAS, the metadata (location, time, date) are automatically extracted and accompany each uploaded image (Figure 2). 


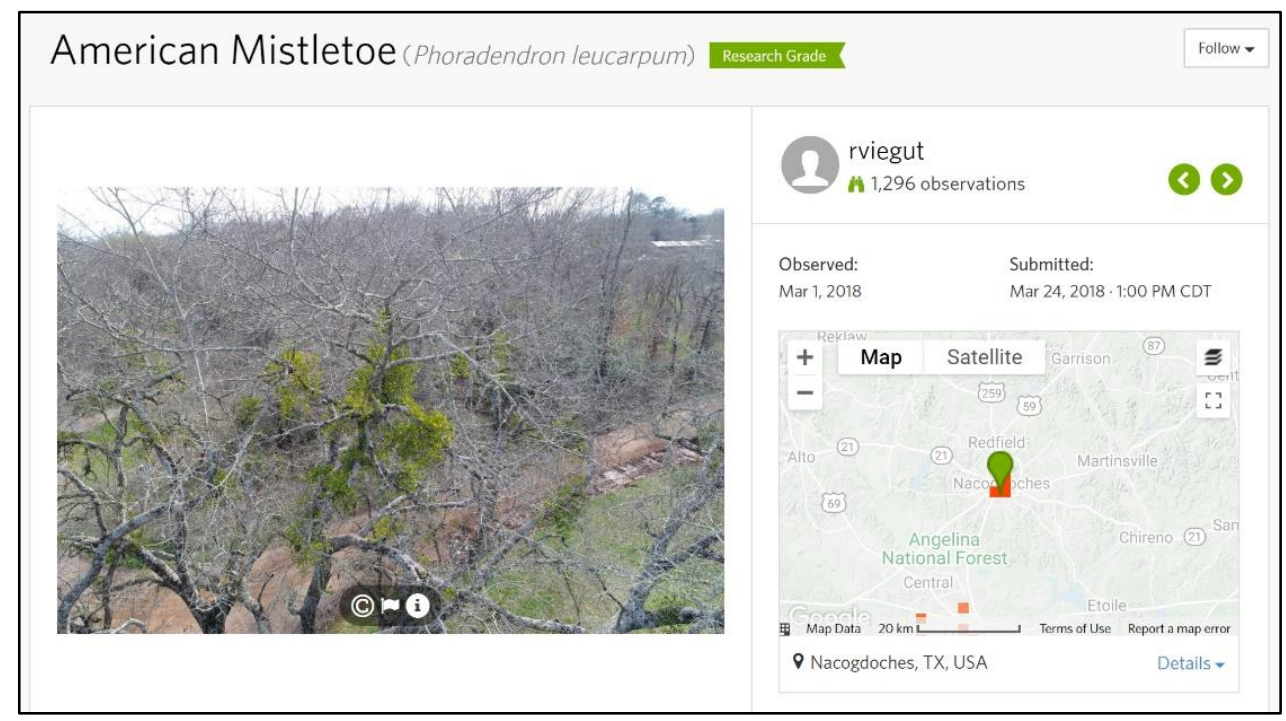

Figure 1. Example of uploaded mistletoe imagery georeferenced to a spatial location within the iNaturalist online interface (Lat: 31.58155, Lon: -94.658164)

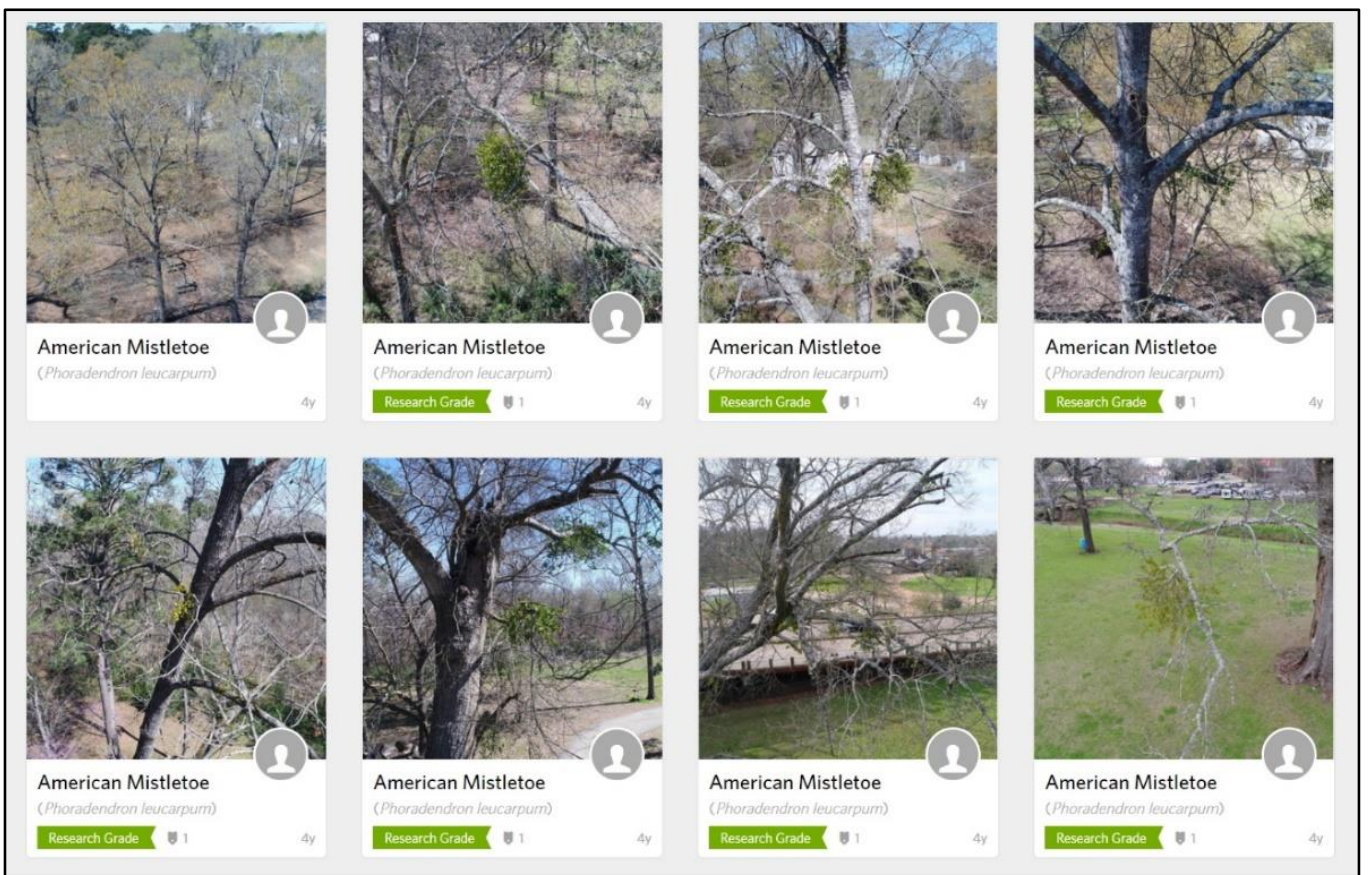

Figure 2. Example of mistletoe and host tree imagery uploaded to the iNaturalist.org website

\subsection{Crapemyrtle Bark Scale}

To assess crapemyrtle bark scale (Acanthococcus lagerstroemiae), a recently introduced pest in the United States, crapemyrtles (Lagerstroemia spp.) were located with drones by students and examined for the bark scale on the SFASU campus in Nacogdoches, Texas. The bark scale feeds on both leaves and stem of crapemyrtle with the nymphs producing secretions that result in high concentrations of sooty mold impairing photosynthesis and growth and well as turn the bark a distinctive, easily identifiable dark color (Wang et al., 2016; Layton, 2019). A combination of a DJI Phantom 4 Pro using the app DJI Go 4 and the camera on a smartphone (for crapemyrtles close to buildings) were used to record both the host tree and signs and symptoms of the bark scale (Figure 3).

A total of 674 trees located by the UAS and 150 located by smartphone were assessed with 60 having bark scale. Following the UAS survey, 50 crapemyrtles infested with bark scale were removed by the university and replaced 
with spire oak. The record of both the host and the bark scale were entered into the Drones and Biodiversity iNaturalist project (https://www.inaturalist.org/projects/drones-and-biodiversity). The image taken is 5,472 by 3,678 pixels with the DJI Phantom 4 camera FC6310 (data extracted from the iNaturalist website) supplied with the UAS.

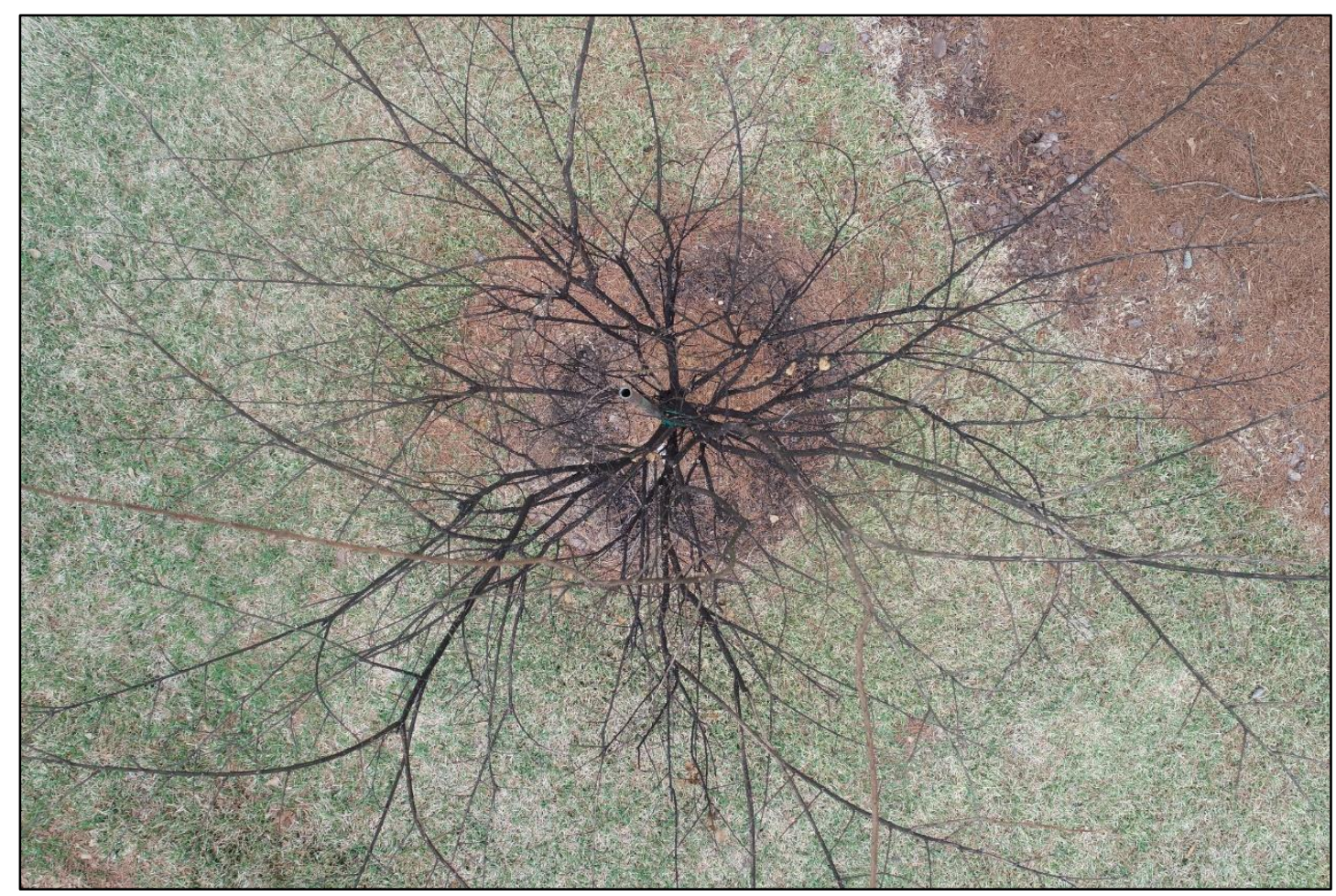

Figure 3. Crapemyrtle infested with crapemyrtle bark scale. Image taken with a DJI Phantom 4 Pro UAS (Lat.:

$$
\text { 31.618233, Lon.: -94.648959) }
$$

\subsection{Red Imported Fire Ant}

The red imported fire ant (RIFA) (Solenopsis invicta) is an invasive species and was introduced in Texas in 1953 with over 56 million acres (22.67 million hectares) now infested. Rationale for inventory of RIFA includes analyzing their distribution in city parks for control potential (Lard et al., 2002). Surveys for RIFA in pastures include fixed plot size and walking transects to locate nest mounds (Steele et al., 2020). To investigate the feasibility of locating RIFA in city parks, a DJI Phantom 4 Pro was used by students to assess the overall park for RIFA mound locations (Figure 4). 


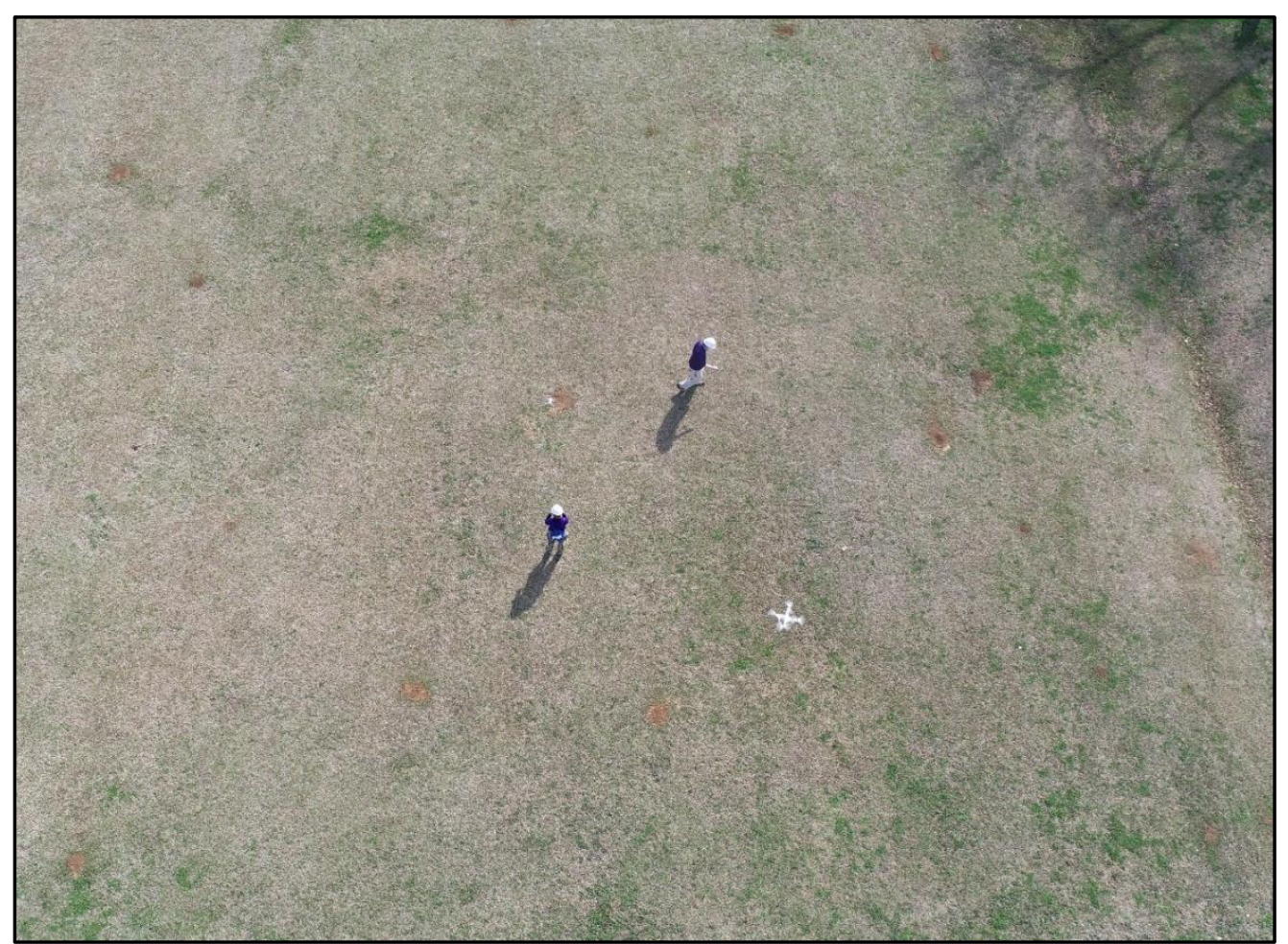

Figure 4. Initial DJI Phantom 4 Pro flight to detect nest mounds of the red imported fire ant

This information was used to guide DJI Mavic Mini and DJI Mavic Mini 2 UASs (Figures 5 and 6) to further investigate potential RIFA locations. The UASs were flown by student drone pilots 3-4 m above the ground to take images of each nest mound (Figure 6). Images with latitude and longitude location data were entered into iNaturalist projects Drones and Biodiversity, Fire Ants of East Texas, and Insects of Texas, provided a visual map of the locations of the nest mounds, increasing the scope and availability of the iNaturalist data.

\section{Conclusions}

We highlight the method of using UASs student scientists to contribute data for iNaturalist and enhance science education to expand the collection ability for citizen scientists. Drones are an effective tool to bridge learning and experimentation to communicate science (Sattar, Tamatea, \& Nawaz, 2017). As UASs give accurate location at nadir (directly above the species located) when comparing with phone images which are generally taken at a distance, this increases the accuracy of the iNaturalist database. Students using UASs to communicate science with their projects have a better understanding of natural resources and ecosystems. The training program implemented (Unger, Kulhavy, Busch-Petersen, \& Hung, 2016) both enhanced the quality of the data, while leading to additional UAS pilots passing the FAA Remote Pilot exam. UASs are able to expand collection of images of species not readily available from ground-based smartphones or digital cameras, and also enables user to have a larger view of the study site. The addition of the iNaturalist project Drones and Biodiversity formalized the capture of the data and expanded student use and citizen scientists uploading data for both teaching and research projects. For safety with UAS, the FAA implemented the Recreational UAS Safety Test (TRUST) for hobbyists and recreational pilots for aeronautical safety knowledge and rules for operating UAS (FAA, 2021). Data from the UASs were downloaded and uploaded to the website either as single records or batch processed. The continued use of UASs will increase the accuracy of any observation and expand the data collection potential of observations on numerous citizen science databases, including iNaturalist. UASs are becoming increasingly integrated in scientific studies to increase the accuracy and precision of identification and quantification of natural resources. 


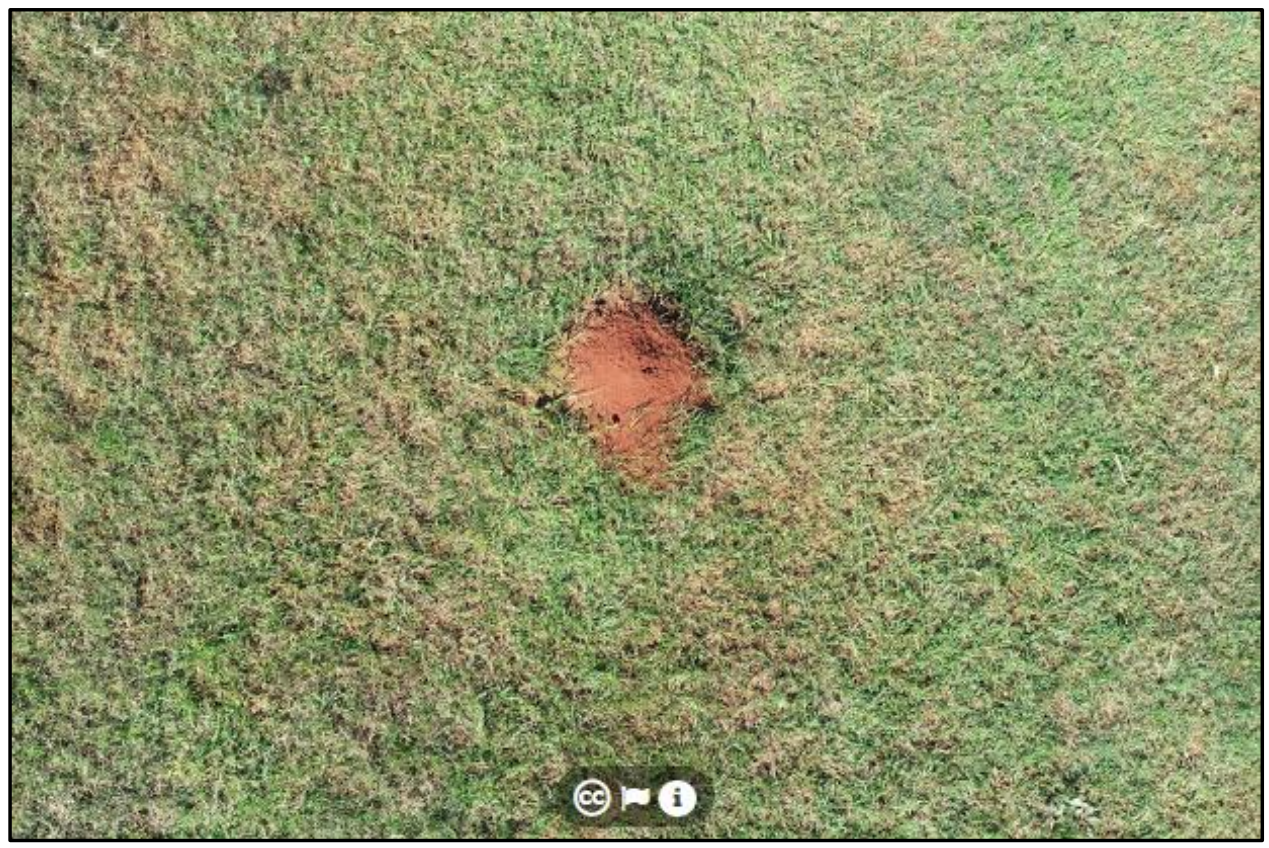

Figure 5. Location of a red imported fire ant (RIFA) nest mound using a DJI Phantom 4 Pro UAS, (Lat.: 31.56067, Lon.: -94.517122)

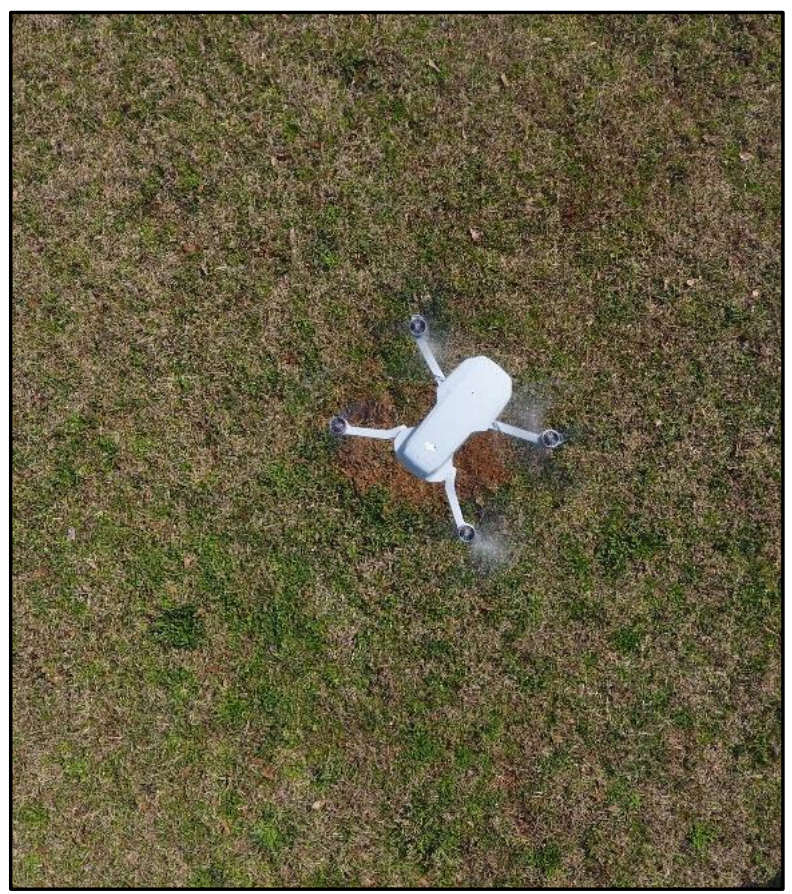

Figure 6. Locating a fire ant mound using the DJI Mavic Mini UAS

For natural resources, we present how UASs can expand the teaching and research base for investigating complex environmental, ecological and economic issues by using high end technology, working outdoors and making a difference in natural resource management training (Bullard et al., 2014). For student use of UASs for iNaturalist, a four-step process was implemented as part of mentored undergraduate research including UAS assembly and safety/FAA (Federal Aviation Administration) rule training; performing a controlled flight to acquire both images and video as both a pilot in command and a visual observer; downloading UAS data into GIS (Geographic Information System) software for quantitative analysis; and demonstrating use of the UAS acquired imagery in teaching and research. We encourage future citizen science participants and student led projects to explore the use of UASs and 
their continued integration into assessing and quantifying biodiversity for science

\section{Acknowledgements}

This project was completed using McIntire-Stennis funds administered by the Arthur Temple of Forestry and Agriculture, Stephen F. Austin State University.

\section{References}

Altrudi, S. (2021). Connecting to nature through tech? The case of the iNaturalist app. Convergence: The International Journal of Research into New Media Technologies, 2021, 27(1), 124-141. https://doi.org/10.1177\%2F1354856520933064

Aristeidou, M., Herodotou, C., Ballard, H. L., Young, A. N., Miller, A. E., Higgins, L., \& Johnson, R. F. (2021) Exploring the participation of young citizen scientists in scientific research: The case of iNaturalist. PLOS ONE, 16(1), e0245682. https://doi.org/10.1371/journal.pone.0245682

Boone, M. E., \& Basille, M. (2019). Using iNaturalist to contribute your nature observations to science. IFAS Extension, University of Florida, WEC413, 5. https://doi.org/10.32473/edis-uw458-2019

Bullard, S. H., Stephens Williams, P., Coble, T., Coble, D. W., Darville, R., \& Rogers, L. (2014). Producing "society ready" foresters: A research-based process to revise the Bachelor of Science in Forestry curriculum at Stephen F. Austin State University. Journal of Forestry, 112, 354-360. https://doi.org/10.5849/jof.13-098

Cohen, C., Cheney, L., Duong, K., Lea, B., \& Unno, Z. P. (2015). Identifying opportunities in citizen science for academic libraries. Issues Science Technology Librarians, 79, 1-13. doi: 10.5062/F4BR8Q66.

Evans, I. J., Jones, T. H., Pang, K., Evans, M. N., Saimin, S., \& Goossens, B. (2015). Use of drone technology as a tool for behavioral research: a case study of crocodilian nesting. Herpetology Conservation Biology, 10(1), 90-98. http://orca.cardiff.ac.uk/id/eprint/77762

Federal Aviation Administration. (2021). The Recreational UAS Safety Test (TRUST). FAA https://www.faa.gov/uas/recreational_fliers/knowledge_test_updates/

He, Y., \& Wiggins, A. (2015). Community-as-a-Service: Data Validation in Citizen Science. 4th International Workshop on Methods for Establishing Trust of (Open) Data, Bethlehem, PA. https://doi.org/10.1145/2818048.2820063

Hoffmann, S., Thompson Klein, J., \& Pohl, C. (2019). Linking transdisciplinary research projects with science and practice at large: introducing insights from knowledge utilization. Environmental Science \& Policy, 102, 36-42. https://doi.org/10.1016/j.envsci.2019.08.011

Hugenholtz, C. H., Moorman, B. J., Riddell, K., \& Whitehead, K. (2012). Small unmanned aircraft systems for remote sensing and earth science research. Eos, 93(25), 236-236. https://doi.org/10.1029/2012EO250005

Kosmala, M., Wiggins, A., Swanson, A., \& Simmons, B. (2016). Assessing data quality in citizen science. Frontiers in Ecology and the Environment, 14(10), 551-560. https://doi.org/10.1002/fee.1436

Kulhavy, D. L., Schalk, C. M., Viegut, R. A., Unger, D. R., Shockley, S. W., \& Hung, I. (2019). Using unmanned aircraft systems (UAS) to quantify mistletoe in urban environments. Urban Naturalist, 20, 1-10.

Lard, C. L., Willis, D. B., Salin, V., \& Robinson, S. (2002). Economic assessments of red imported fire ant on Texas' urban and agricultural sectors. Southwestern Entomologist (Supplement 25), 123-137.

Layton, B. (2019). Crape myrtle bark scale identification and control. Mississippi State University Extension Publication 2938, 8.

Mazumdar, S., Ceccaroni, L., Piera, J., Hölker, F., Berre, A., Arlinghaus, R., \& Bowser, A. (2018) Citizen science technologies and new opportunities for participation. In: Hecker, S., Haklay, M., Bowser, A., Makuch, Z., Vogel, J. and Bonn, A. (eds.) Citizen Science - Innovation in Open Science, Society and Policy. (pp. 303-320). UCL Press: London. https://doi.org/10.2307/j.ctv550cf2.28

Miller, J. E. D., Ziter, C. D., \& Koontz, M. J. (2021). Fieldwork in landscape ecology. In: Francis, R. A., Millington, J. D. A., Perry, G. L.W. and Minor, E. S. The Rutledge Handbook of Landscape Ecology (pp. 219-229). Rutledge and Rutledge: NY. https://doi.org/10.4324/9780429399480-14

Nugent, J. (2018). iNaturalist citizen science for 21st-century naturalists. Science Scope, 41(7), 12-13. https://doi.org/10.2505/4/ss18_041_07_12 
Nugent, J., \& Thripplehorn-Hunter, K. (2017). Experimental learning in the 21st century: Service learning and civic engagement opportunities in the science classroom. Science Education and Civic Engagement, 9(2), 40-46.

Pimm, S. L., Alibhai, S., Bergl, R., Dehgan, A., Giri, C., Jewell, Z., Joppa, L., Kays, R., \& Loarie, S. (2015). Emerging technologies to conserve biodiversity. Trends in Ecology and Evolution, 30(11), 685-696. https://doi.org/10.1016/j.tree.2015.08.008

Sattar, F., Tamatea, L., \& Nawaz, M. (2017). Droning the pedagogy: Future prospect of teaching and learning. International Journal of Education and Pedagogical Sciences, 11, 1659-1664. http://scholar.waset.org/1307-6892/10007926

Steele, C. H., King, J. R., Boughton, E. H., \& Jenkins, D. (2020). Distribution of the red imported fire ant Solenopsis invicta (Hymenoptera: Formicidae) in Central Florida pastures. Environmental Entomology, 49, 956-962. https://doi.org/10.1093/ee/nvaa037

Sullivan, B. L., Wood, C. L., Iliff, M. J., Bonney, R. E., Fink, D., \& Kelling, S. (2009). eBird: A citizen-based bird observation network in the biological sciences. Biological Conservation, 142(10), 2282-2292. https://doi.org/10.1016/j.biocon.2009.05.006

Teacher, A. G. F., Griffiths, D. J., Hodgson, D. J., \& Inger, R. (2013). Smartphones in ecology and evolution: a guide for the app-rehensive. Ecological Evolution, 3(16), 5268-5278. https://doi.org/10.1002/ece3.888

Unger, D. R., Kulhavy, D. L., Busch-Petersen, K., \& Hung, I. (2016). Integrating faculty led service learning training to quantify height of natural resources from a spatial science perspective. International Journal of Higher Education, 5, 104-116. https://doi.org/10.5430/ijhe.v5n3p104

Unger, D. R., Kulhavy, D. L., Hung, I., Zhang, Y., \& Stephens Williams, P. (2019). Integrating drones into a natural-resource curriculum at Stephen F. Austin State University. Journal of Forestry, 117, 398-405. https://doi.org/10.1093/jofore/fvz031

van Horn, G., Mac Aodha, O., Song, Y., Cui, Y., Sun, C., Shepard, A., Adam, H., Perona, P., \& Belongie, S. (2018). The iNaturalist species classification and detection dataset. In IEEE/CVF Conference on Computer Vision and Pattern Recognition. IEEE, Piscataway, NJ, 8769-8778. https://doi.org/10.1109/CVPR.2018.00914

Wagenknecht, K., Woods, T., Nold, C., Rüfenacht, S., Voigt-Heucke, S., Caplan, A., Hecker, S., \& Vohland, K. (2021). A question of dialogue? Reflections on how citizen science can enhance communication between science and society. JCOM, 20(03), A13. https://doi.org/10.22323/2.20030213

Wang, Z., Chen, Y., Gu, M., Vafaie, E., Merchant, M., \& Diaz, R. (2016). Crapemyrtle bark scale: A new threat for crapemyrtles, a popular landscape plant in the U.S. Insects, 7(4), 78. https://doi.org/10.3390/insects7040078

Whitehead, K., \& Hugenholtz, C. H. (2014). Remote sensing of the environment with small unmanned aircraft systems (UASs), part 1: a review of progress and challenges. Journal of Unmanned Vehicle Systems, 2(3) 69-85. https://doi.org/10.1139/juvs-2014-0006

\section{Copyrights}

Copyright for this article is retained by the author(s), with first publication rights granted to the journal.

This is an open-access article distributed under the terms and conditions of the Creative Commons Attribution license (http://creativecommons.org/licenses/by/4.0/). 